\title{
Energy saving system of cascade variable frequency induction electric drive
}

\author{
V. N. Meshcheryakov ${ }^{1, *}$, D. V. Lastochkin ${ }^{1}, Z . M$. Shakurova $^{2}$, and $S$. Valtchev $^{3}$ \\ ${ }^{1}$ Lipetsk State Technical University, Lipetsk, Russia \\ ${ }^{2}$ Kazan State Power Engineering University, Kazan, Russia \\ ${ }^{3}$ Universiade Nova de Lisboa, Caparica, Portugal
}

\begin{abstract}
This paper discusses the wound rotor induction motor and variable-frequency drive (VFD) that regulates the stator voltage frequency. The stator and rotor windings are connected to a common electrical circuit. The slip energy of the motor goes to the DC link and feeds the stator winding of the motor. The block diagram of the electric drive, the equivalent circuit and the basic characteristic of the cascade VFD are considered. It is shown that the energy-saving mode with a minimum ratio "stator current/torque" is achieved at an angle between vectors of the stator current and the excitation current at the level of 45 degrees. The experimental static mechanical characteristics of the electric drive were obtained. These characteristics provide a limitation of the starting torque.
\end{abstract}

\section{Introduction}

Currently, squirrel-cage induction motors are most widely used in electric drives of industrial mechanisms [1-3]. However, wound rotor induction motor are still used on such mechanisms, as hoisting-and-transport. The parametric systems are applied to control the motor speed [4-5]. Parametric systems are the simplest, however there are large energy losses during the start. The design of the energy-saving control system for starting the wound rotor induction motor is an important task. There are systems [6-7] that add the frequencydependent resistance into the motor rotor circuit during the motor start. Nevertheless, energy losses at the start are also large in these electric drive systems. The frequency control systems are the most economical for induction motors [8-14]. Such systems provide high quality control, while microprocessors are widely used in them [15]. Efficient frequency control can also be applied for wound rotor induction motor. It is reasonable to use an additional cascade connection of the stator and rotor of the motor through rectifier and inverter units.

\section{Key issues and solutions}

There is electrical connection of the stator and rotor windings through a common DC link in this electric drive system of induction motor. Mechanical characteristics of the electric drive are nonlinear, the method of their calculation is considered in the references $[1,2]$. The cascade variable-frequency drive (Figure 1) is made on the basis of induction motor with wound rotor, current inverter and cascade slip energy recovery unit feeding the DC link of the inverter. It contains: 1 - frequency converter based on the current inverter; 2 - induction motor, 3,4 - stator current sensors; 5 - adder of two phase currents of the stator; 6 pulse-width modulation (PWM) current regulator; 7 feedback speed channel; 8 - adder of the speed signals; 9 - speed reference; 10 - speed comparator; 11 - speed regulator; 12 - limitation of instantaneous values reference signal for the squared module of stator current; 13 - setting the instantaneous values of the stator current; 14 - setting the frequency of the rotor current; 15 - adder of angular frequencies; 16, 17 - current sensors of the rotor; 18 - adder of the two phase currents of the rotor; 19 - calculation of the angular frequency of the rotor current; 20 - frequency comparator; 21 forming unit of the signal correction of the stator current module; 22 - rotary speed sensor; 23 - proportional block with coefficient . The current inverter consists of adjustable rectifier 24 and inverter 25 , rectifier 26 is included in the DC link, the inputs of which are connected to the outputs of the rotor windings of the induction motor. The smoothing reactor 27 and the current sensor 28 are also included in the common DC link. The control unit 29 of the rectifier 24 receives a rectified current feedback signal from the sensor 28 and controls the current in the common DC link.

The principles of frequency-current control of the induction motor and synthesis of control system units are considered in $[16,17]$. The principles of frequencycurrent control are most appropriate for the implementation of frequency-cascade control of an induction motor with a wound rotor [19-22].

In the cascade VFD system, the difference between the rectified supply voltage and the EMF of the inverter 25 creates the resulting additional voltage U2, which is

\footnotetext{
* Corresponding author: mesherek@yandex.ru
} 


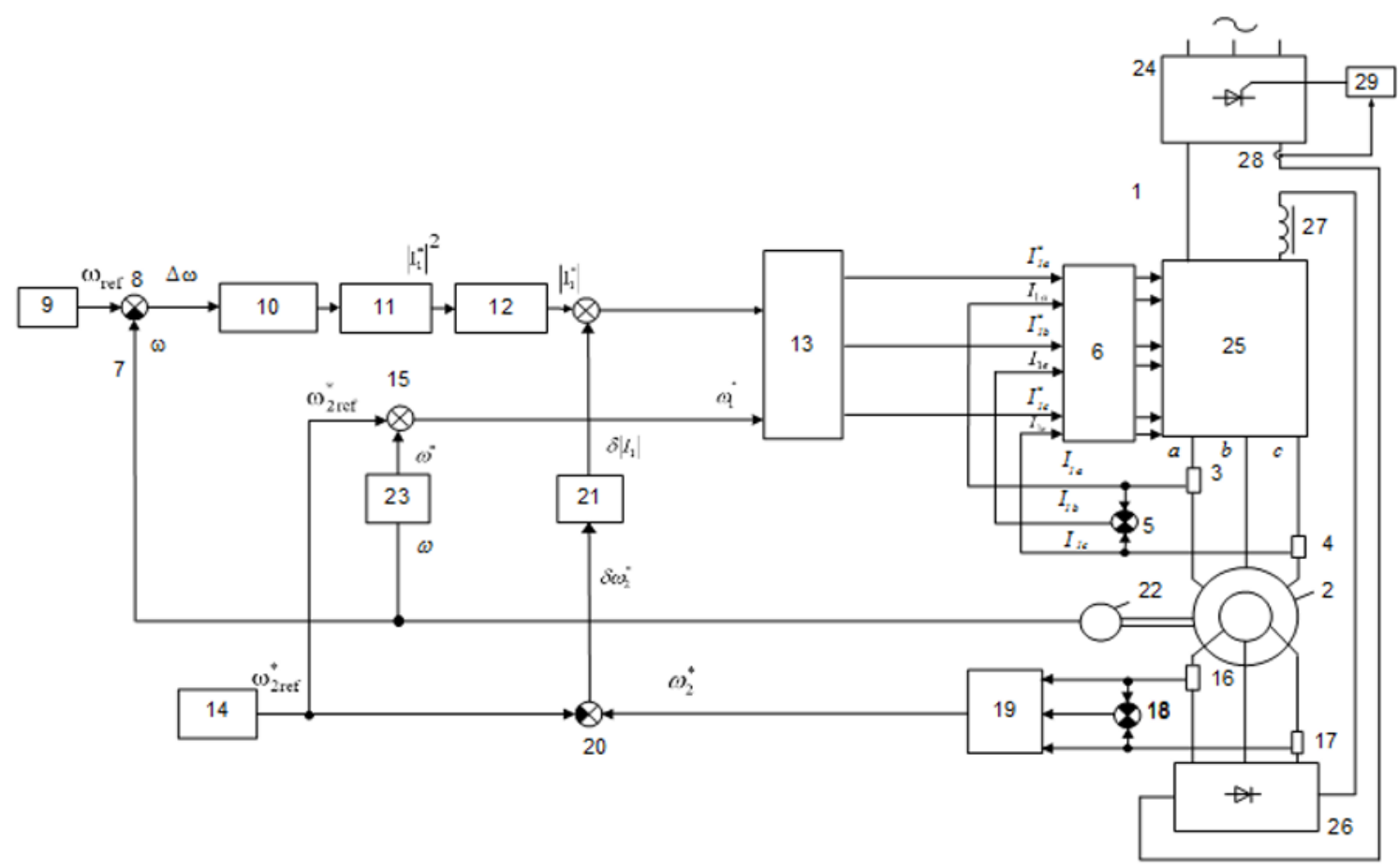

Fig. 1. Block diagram of the frequency-cascade control of an induction motor with a wound rotor with a closed loop of the rotor current frequency stabilization.

introduced into the motor rotor circuit, providing a cascade principle of the electric drive operation. Voltage $\mathrm{U} 2$ is always less than the voltage at the rectifier 26 output. To ensure the stability of the angular frequency of the rotor current, it is necessary to maintain module of the additional voltage in the rotor circuit $\mathrm{U} 2$ at a constant level. The optimal value of the rotor angular velocity deviation from the angular velocity of stator rotating field optU2, in cascade VFD, is:

$$
\Delta \omega_{\mathrm{optU} 2}=\frac{1}{p_{n}} \frac{R_{2}}{L_{2 \sigma}+L_{m}}+\frac{\omega_{1} \cdot U_{2}}{E_{2 \mathrm{\kappa}}}
$$

where $R_{2}$ - resistance of the rotor, $L_{2}$ - inductance dispersion of the rotor winding; $\mathrm{L}_{\mathrm{m}}$ - mutual inductance of the stator and rotor windings; $\omega_{1}-$ frequency of the stator current; $\mathrm{U}_{2}$ - additional voltage introduced in the rotor circuit.

If the optimal value $\Delta \omega_{\text {optU2 }}$ is achieved through introducing back-EMF into the rotor circuit, the motor stator current will be minimal at the given productivity of the electric drive.

In the control system, the unit 19 calculates the circular frequency of the rotor current $\omega_{2}^{*}$ using the signals from the rotor current sensors. The obtained value is compared with the reference value $\omega_{2 \text { ref }}^{*}$. The correction signal $\delta\left|I_{1}\right|$ for the stator current module is produced on the basis of the comparison results.

Regulation of stator rotating field frequency is achieved by control of the current frequency and amplitude of the output inverter, by analogy to the common systems of frequency control of squirrel-cage induction motor.

The equivalent circuit of the electric drive is shown in Figure 2. The voltage balance equation for steadystate operation when bringing all elements of the circuit to the DC circuit has the form

$$
\begin{aligned}
& E_{d 1}=E_{d 0}+E_{d 2 \kappa} \cdot s_{\alpha}-I_{d} \cdot\left[2 \cdot\left(R_{1}+R_{0}+R_{2}\right)+\right. \\
& \left.+\frac{3}{\pi} \cdot\left(x_{0}+\alpha\left(x_{1}+x_{2} \cdot s_{\alpha}\right)\right)+\Delta R_{d}+R_{\mathrm{i}}\right]
\end{aligned}
$$

where $\mathrm{E}_{\mathrm{d} 0}$ - rectified EMF of controlled rectifier; $\mathrm{E}_{\mathrm{d} 1}$ - rectified back-EMF of the stator winding; $\mathrm{E}_{\mathrm{d} 2}$ rectified EMF in the rotor winding; $I_{d}-$ rectified current; $\Delta \mathrm{R}_{\mathrm{d}}$ - total resistance of the valves of the scheme; $\mathrm{R}_{\mathrm{i}}-$ active resistance of the smoothing inductor; $\alpha=\mathrm{f}_{1} / \mathrm{f}_{\mathrm{H}}-$ ratio of the stator current frequency to the rated frequency; $\mathrm{s}_{\alpha}$ - relative slip.

Bringing the resistance of the electric drive circuit elements from the AC circuits to the DC circuit is made in accordance with the expressions

$$
\begin{gathered}
R_{d 0}=2 R_{0}+\frac{3 x_{0}}{\pi} ; \\
\mathrm{R}_{\mathrm{d} 1}=2 \mathrm{R}_{1}+\frac{3 \cdot \alpha \cdot \mathrm{x}_{1}}{\pi} ;
\end{gathered}
$$




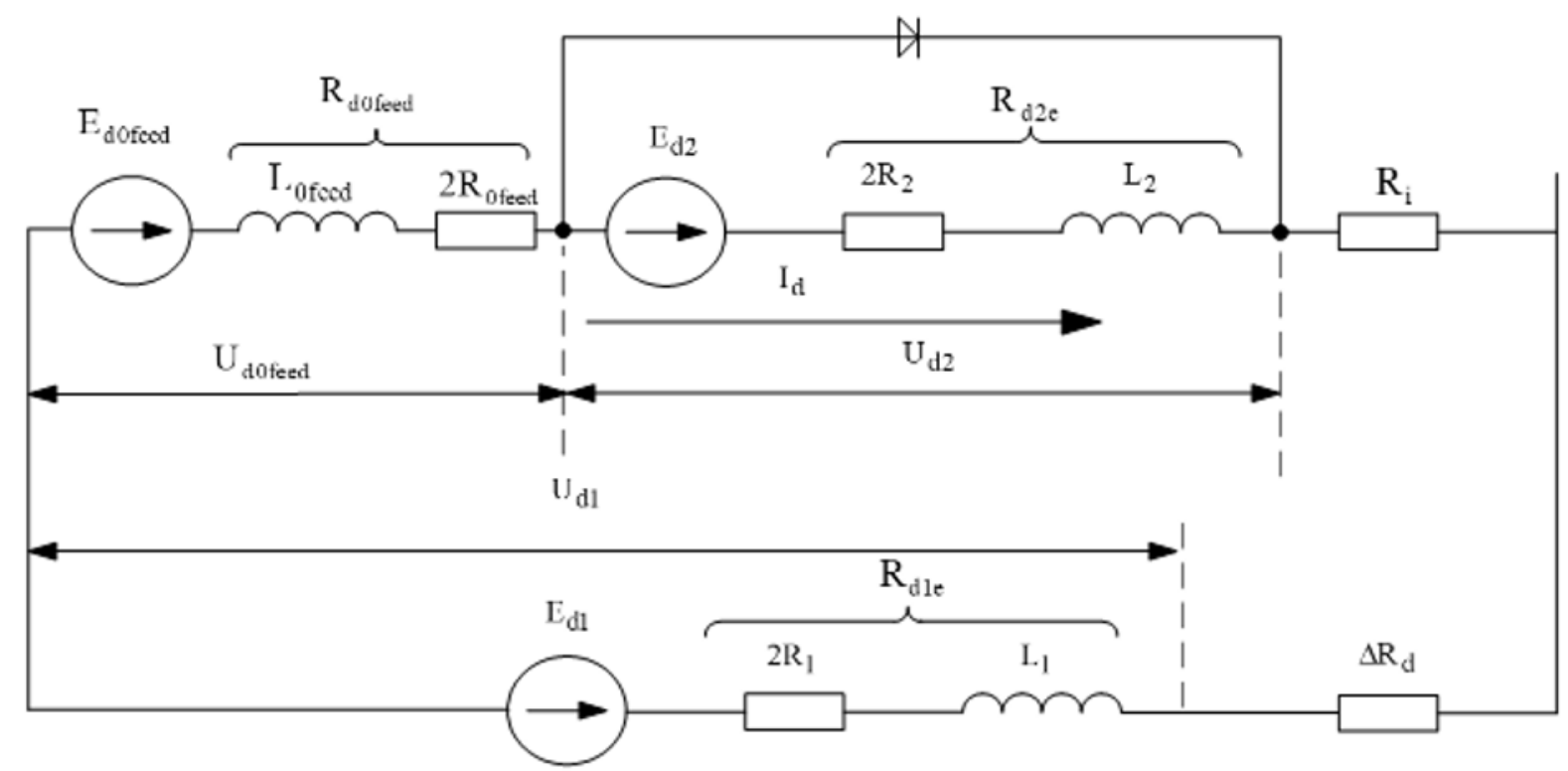

Fig. 2. The equivalent circuit of the cascade variable-frequency drive when bringing the parameters to the DC link.

$$
\mathrm{R}_{\mathrm{d} 2}=2 \mathrm{R}_{2}+\frac{3 \cdot \alpha \cdot \mathrm{x}_{2} \cdot \mathrm{s}_{\alpha}}{\pi}
$$

where $\mathrm{R}_{\mathrm{d} 0}$ - equivalent resistance of the power supply; $\mathrm{R}_{0}, \mathrm{x}_{0}$ - resistance and reactance of the power source; $\mathrm{R}_{\mathrm{d} 1}$ - equivalent resistance of the stator winding; $\mathrm{R}_{1}$, $\mathrm{X}_{1}$ - resistance and reactance of the stator winding; $\mathrm{R}_{\mathrm{d} 2}$ - equivalent resistance of the rotor winding; $\mathrm{R}_{2}$, $\mathrm{X}_{2}$ - resistance and reactance of the rotor winding.

EMF of the supply rectifier is defined as follow

$$
\mathrm{E}_{\mathrm{d} 0}=\mathrm{U}_{0} \cdot \mathrm{K}_{\mathrm{u}} \cdot \cos \alpha_{\mathrm{y}},
$$

where $\mathrm{U}_{0}$ - phase voltage of the supply network; $\kappa_{\mathrm{u}}-$ phase voltage reduction factor to the DC circuit $\left(\kappa_{\mathrm{u}}=\frac{3 \sqrt{6}}{\pi}\right) ; \alpha_{\mathrm{y}}$-control angle of the rectifier.

Only supply rectifier consumes reactive power from the power grid in the cascade VFD with current inverter. The control angle of rectifier can be adjusted in the range $0^{0} \leq \alpha \leq 30^{0}$. In this case, a higher value of the motor speed corresponds to a lower value of the control angle $\alpha$, and therefore to a lower consumption of reactive current from the grid.

The ratio between the current in the rectified circuit and the stator and rotor currents is determined in the absence of equalizing currents by the following expressions

$$
\begin{aligned}
& \mathrm{I}_{1}=\mathrm{k}_{\mathrm{s}} \cdot \mathrm{k}_{\mathrm{I}} \cdot \mathrm{I}_{\mathrm{d}}=\mathrm{k}_{\mathrm{s}} \cdot \frac{\sqrt{6}}{\pi} \cdot \mathrm{I}_{\mathrm{d}} ; \\
& \mathrm{I}_{2}=\mathrm{k}_{\mathrm{r}} \cdot \mathrm{k}_{\mathrm{I}} \cdot \mathrm{I}_{\mathrm{d}}=\mathrm{k}_{\mathrm{r}} \cdot \frac{\sqrt{6}}{\pi} \cdot \mathrm{I}_{\mathrm{d}},
\end{aligned}
$$

where $k_{I}=\frac{\sqrt{6}}{\pi}-$ coefficient linking the effective current in the AC circuit of the bridge converter with the current in the rectified circuit; $\mathrm{k}_{\mathrm{S}}$ - coefficient related to the output current of the inverter and the motor stator current (depends on the capacitance of the output capacitors in the current inverter); $\mathrm{k}_{\mathrm{r}}-$ coefficient related to the output current of the inverter and the motor rotor current (depends on the presence of equalizing currents shunting the bridge rectifier in the rotor circuit).

The currents of the stator and the rotor can be considered equal to each other

$$
\mathrm{I}_{1}=\mathrm{I}_{2}
$$

Therefore, the nominal values of the stator and rotor currents should be approximately equal and differ by no more than $8-10 \%$. As a result, when changing the operating mode of the electric drive, the angle $\varphi_{0}$ between vectors of the stator current and the magnetization current is approximate constant

$$
\varphi_{0}=\arcsin \frac{\mathrm{I}_{2} \cdot \cos \delta}{\mathrm{I}_{1} \cdot \mathrm{K}_{\mathrm{e}}}=\arcsin \frac{\cos \delta}{\mathrm{K}_{\mathrm{e}}},
$$

where $\mathrm{K}_{\mathrm{e}}$ - the transformation coefficient of the motor; $\delta$ - the angle between vectors of the rotor current and the EMF of the rotor winding.

Since the angle $\delta$ is very small, even when it changes due to the changes in other parameters of the system, $\cos \delta$ changes slightly and is close to 1 .

The current in the rectified circuit and the electromagnetic torque of the motor in the open system are determined by the formulas [22]: 


$$
\begin{aligned}
& \mathrm{I}_{\mathrm{d} \alpha}=\frac{\mathrm{U}_{\mathrm{d} 0} \cdot \rho \cdot \frac{\gamma}{\alpha}}{1+\left[2 \cdot\left(\mathrm{R}_{1}+\mathrm{R}_{2}\right)+3 \cdot \frac{\mathrm{x}_{1} \cdot \alpha}{\pi}+\mathrm{R}_{\mathrm{d} \Sigma}\right] \cdot \frac{\rho}{\alpha}-\frac{\beta}{\alpha}\left(\frac{1}{\kappa_{\mathrm{e}}}-3 \cdot \frac{\mathrm{x}_{2} \cdot \mathrm{\kappa}}{\pi}\right)} \\
& M_{\alpha}=\frac{1,35}{\omega_{0} \cdot \alpha} \cdot\left(\frac{\sqrt{3} \cdot x_{m} \cdot \alpha \cdot \sqrt{1-\frac{1}{\kappa_{e}^{2}}-2 \cdot \frac{x_{2} \cdot \alpha}{x_{m} \cdot \alpha}}}{\kappa_{e} \cdot \kappa_{c x}}-\frac{x_{2} \cdot \alpha}{\sqrt{2}}\right) \cdot I_{d}^{2}= \\
& =\frac{1,35}{\omega_{0}} \cdot\left(\frac{\left.\sqrt{3} \cdot x_{m} \cdot \sqrt{1-\frac{1}{\kappa_{e}^{2}}-2 \cdot \frac{x_{2}}{x_{m}}}-\frac{x_{2}}{\sqrt{2}}\right) \cdot I_{d}^{2}}{\kappa_{e} \cdot \kappa_{c x}}\right)
\end{aligned}
$$

Figure 3 shows the calculated using the expressions (7-12) dependences of the angle $\varphi_{0}$ on the stator current relative value $\mathrm{I} / \mathrm{I}_{\mathrm{N}}$ in the cascade VFD system. From these graphs it can be seen that the greatest ratio of "stator current/torque" is achieved when $\varphi_{0}=45^{\circ}$, which is typical for variable-frequency electric drive systems $[23,24]$. This mode is energy-saving for the system. In order to implement this energy-saving mode, the value of the transformation coefficient of the woundrotor induction motor should be close to $\mathrm{k}_{\mathrm{e}}=1.4$ in accordance with the expression (10).

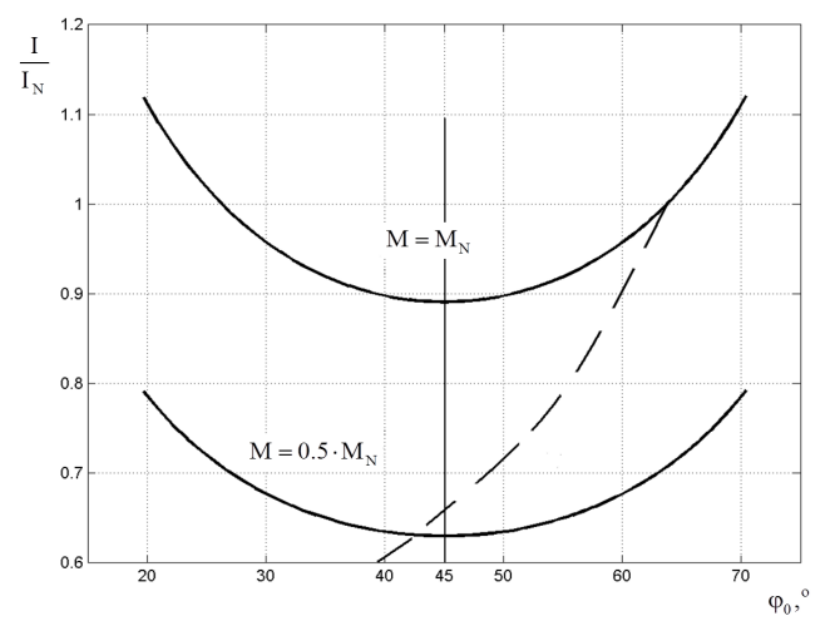

Fig. 3. Dependence of the stator current on the angle at fixed torque values $(\mathrm{M}=$ const $)$.

\section{Results of experimental studies}

The experimental mechanical characteristics of the cascade variable-frequency drive of induction motor with a wound rotor MTF012-6 are shown in Figure 4.

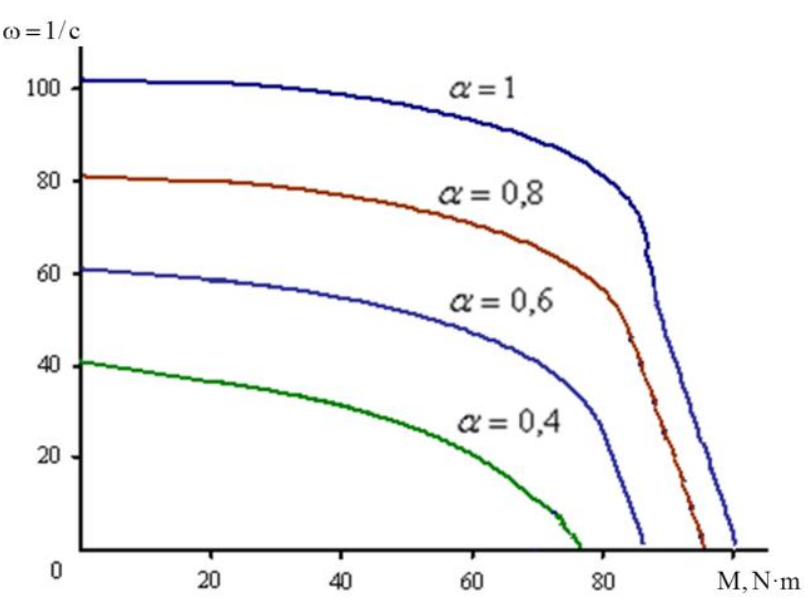

Fig. 4. Experimental static mechanical characteristics of cascade variable-frequency drive ( $\alpha=\omega_{1} / \omega_{0 \mathrm{H}}$ ).

Mechanical characteristics are nonlinear. In the area of small slips, they coincide with the mechanical characteristics of the induction motor with a shortcircuited wound rotor. On the starting part, the mechanical characteristics have a low stiffness. Such mechanical characteristics of the electric drive are required for hoisting-and-transport mechanisms and excavators [25].

\section{Conclusion}

1. In the cascade variable-frequency drive system, it is feasible to use induction motors with a wound rotor with the rated values of the transformation coefficient close to $\mathrm{k}_{\mathrm{e}}=1.4$, while the angle will be close to the optimal value of 45 degrees, and the electric drive will operate in an energy-saving mode;

2. The cascade variable-frequency drive with the mechanical characteristics of the excavator type is appropriate to use on the mechanisms operating in an 
intermittent mode, in particular to a hoisting-andtransport mechanisms.

This research was supported by grant RFBR 19-48-480001 "Development, investigation and optimization of energy-saving electrical and electrically driven automated systems for plasma, electrometal slag and induction technologies and units".

\section{References}

[1] I. Boldea, A. Moldovan, L. Tutelea, Scalar $V / f$ and I-f control of AC motor drives: An overview.Intl Aegean Conference on Electrical Machines \& Power Electronics (ACEMP), Intl Conference on Optimization of Electrical \& Electronic Equipment (OPTIM) \& 2015 Intl Symposium on Advanced Electromechanical Motion Systems (ELECTROMOTION) (Side) 8-17 (2015)

[2] J. You, M. Liu, J. Ma, H. Jia, Modeling and Analyse of Induction Motor Drive System with Consideration of DC Bus Stabilization and Control Performance. 8th International Power Electronics and Motion Control Conference. Hefe 1362-1368 (2016)

[3] J.M. Peña, E.V. Díaz, Implementation of $V / f$ scalar control for speed regulation of a three-phase induction motor. ANDESCON. Arequipa. 1-4 (2016)

[4] S. Lesan, M.S. Smiai, W. Shepherd, Control of wound rotor induction motor using thyristors in the secondary circuits. Industry Applications Society Annual Meeting 32(2), 335-344 (1996)

[5] P.R. Basu, A Variable Speed Induction Motor Using Thyristors in the Secondary Circuit. IEEE Transactions on Power Apparatus and Systems vol. PAS-90(2), 509-514 (1971)

[6] M. Ayyadurai, B.P. Singh, C.S. Jha, R. Arockiasamy, On the Speed Control of Wound-Rotor Induction Motors Using Rotor Impedance Control. IEEE Transactions on Power Apparatus and Systems, vol. PAS-98(5), 1489-1496 (1979)

[7] W. Shepherd, G.R. Slemon, Rotor Impedance Control of the Wound-Rotor Induction Motor. Transactions of the American Institute of Electrical Engineers. Part III: Power Apparatus and Systems, 78(3), 807-814 (1959)

[8] F. Blaschke, A New Method for Structural Decoupling of A.C. Induction Machines. Proceedings of the Conference Rec. IFAC, Duesseldorf, Germany (1971)

[9] I. Takahashi, T. Noguchi, A New Quick Response and High Efficiency Control Strategy for an Induction Motor. IEEE Trans. Ind. Appl. IA-22, 820827 (1985)

[10] H. Rehman, L. Xu, Alternative energy vehicles drive system: Control, flux and torque estimation, and efficiency optimization. IEEE Trans. Veh. Technol, 60, 3625-3634 (2011)

[11] J. Rodriguez, R.M. Kennel, J.R. Espinoza, M. Trincado, C.A. Silva, C.A. Rojas, High performance control strategies for electrical drives: an experimental assessment. IEEE Trans. Ind. Electron, 59, 812-820 (2012)

[12] L.A. Brooks, J.L. Castro, E.L. Castro, Speed and position controller using indirect filed-oriented control: A classical control approach. IEEE Trans. Ind. Electron, 61, 1928-1943 (2014)

[13] H. Rehman, An integrated starter alternator and low cost, high performance drive for vehicular applications. IEEE Trans. Veh. Technol. 57, 1454-1465 (2008)

[14] W. Sung, J. Shin, Y. Jeong, An energyefficient and robust control for high-performance induction motor drive with an application in electric vehicles. IEEE Trans. Veh. Technol. 61, 3394-3405

[15] H. Rehman, R.J. Hampo, A Flexible High Performance Advanced Controller for Electric Machines. Proceedings of the IEEE APEC 2000 Conference Record, New Orleans, LA, USA, 6-10, 939-943 (2000)

[16] I. Braslavsky, Z. Ishmatov, V. Polyakov, Energy Saving induction electric drive. Moscow: Academy. 256 (2004)

[17] V.N. Brodovsky, Drives with frequencycurrent control. M.: Energy.168 (1974)

[18] Onishchenko G.B., Lokteva I.L., Induction valve stages and dual power engines. M.: Energy 200 (1979)

[19] N.I. Shulakov, E.I. Medvedev, Inductionvalve cascade with sequential motor excitation Izv. higher educational. Electromechanics. 1, 47 - 54 (1988)

[20] V.N. Meshcheryakov, V.V. Danilov, O.V. Meshcheryakova, D.V. Lastochkin, Patent for utility model RU. № 180843. Device for control of induction motor with phase rotor / Publ. 03.07.2018, Byul. 19, (2018)

[21] V.N. Meshcheryakov, V.V. Fedorov, 1998 Induction-valve cascade with inverter in the stator circuit and a common link DC. Electrical Engineering. 6, 47-50

[22] V.N. Meshcheryakov, Dynamics of Electromechanical systems of lifting and transport mechanisms with induction electric drive. Monograph. Lipetsk. Lstu 120 (2002)

[23] V.N. Meshcheryakov, P.N. Levin, T.V. Sinyukova, Improving the efficiency of the search algorithm to optimize energy saving by forming a magnetic flux of an induction motor. Devices and systems, management, control, diagnostics 6, 25-30 (2014)

[24] V.N. Meshcheryakov, V.S. Cherkasova, O.V. Meshcheryakova, Correction of vector control system of induction electric drive. Control systems and information technologies, 3(61), 36-38 (2015)

[25] V.I. Klyuchev, Limitation of dynamic loads of the electric drive. M., Energy 319 (1971) 